\title{
A New Problem with the Twin Paradox
}

\author{
Koshun Suto ${ }^{1}$ \\ ${ }^{1}$ Chudaiji Buddhist Temple, Isesaki, Japan \\ Correspondence: Koshun Suto, Chudaiji Buddhist Temple, 5-24, Oote-Town, Isesaki, 372-0048, Japan. \\ Tel: 81-270-23-9980. E-mail: koshun_suto129@mbr.nifty.com
}

Received: February 18, 2017

doi:10.5539/apr.v9n2p77

\author{
Accepted: March 10, 2017 \\ Online Published: March 20, 2017 \\ URL: https://doi.org/10.5539/apr.v9n2p77
}

\begin{abstract}
This paper discusses the "triplet thought experiment" in which accelerated motion is eliminated from the famous twin paradox thought experiment of the special theory of relativity (STR). The author considers the coordinate systems of an inertial frame $\mathrm{M}$ and rocket A moving at constant speed relative to each other. First, an observer in inertial frame $\mathrm{M}$ performs the triplet thought experiment, and it is confirmed that the delay in time which elapses in the moving system agrees with the predictions of the STR. However, the delay in time predicted by the STR is observed even in the case when an observer A in rocket A carries out the triplet thought experiment. Before starting movement at constant velocity, rocket A experiences accelerated motion. The coordinate system of rocket A cannot be regarded physically as a stationary system. Even so, observer A observes the delay predicted by the STR. If the previous, traditional interpretation is assumed to be correct, observer A will never observe a delay in time agreeing with the predictions of the STR. To avoid paradox, the previously proposed traditional interpretation must be revised.
\end{abstract}

Keywords: Twin Paradox, Triplet Thought Experiment, Special Theory of Relativity, Minkowski Diagram, Relativistically Stationary System

\section{Introduction}

Among the hypothetical paradoxes generated by the special theory of relativity (STR), the twin paradox (or clock paradox) is the most famous.

Suppose two clocks have been synchronized to the current time, and mark time at the same rhythm. Assume that one clock (the first clock) remains stationary in a certain inertial frame, and the other clock (the second clock) is carried away along an arbitrary path, eventually returning to the departure point. The STR predicts that, at this time, the second clock will be delayed compared to the first clock.

To use a modern example, if the older of two twin astronauts returns from a trip through space, he will find that he is younger than his younger brother who remained on earth. This problem has been vigorously debated in the past, and today the issue is thought to be settled (Holton, 1963). The tradition view put forward to avoid the paradox is as follows.

"The coordinate system of the second clock moving with respect to the inertial frame undergoes accelerated motion, and thus an asymmetry exists between the two coordinate systems. The side which has moved is clearly the second clock, and thus it is natural for the second clock to be delayed."

A coordinate system which has attained movement at constant velocity through accelerated motion cannot be regarded physically as a stationary system.

However, this paper presents a thought experiment performed in a coordinate system which cannot be regarded as this stationary system, and in this experiment a delay of time is observed which agrees with the prediction of the STR. However, in order to avoid discussion of the accelerated motion treated in the twin paradox thought experiment, here the author considers the "triplet thought experiment."

In another paper, the author has presented thought experiments enabling discrimination of two types of inertial frames (Suto, 2010, 2015).

Therefore, in this paper, it should be permissible to carry out thought experiments using an inertial frame in which light propagates isotropically (In this paper, an inertial frame in which light propagates isotropically will be defined as "Michelson's stationary system") (see Appendix). 


\section{Triplet thought Experiment 1 Performed by Observer M}

Rocket A is moving at constant velocity of $3 c / 5$ in the $x$-axis direction of "Michelson's stationary system." (In the following, "Michelson's stationary system" may be indicated as $S_{\mathrm{M}}$, and the coordinate system of rocket A as $S_{\mathrm{A}}^{\prime}$. The "M" in $S_{\mathrm{M}}$ is the $\mathrm{M}$ in "Michelson".)

There is an observer $\mathrm{M}$ at the origin $\mathrm{O}$ of the $x$-axis of $S_{\mathrm{M}}$, and $\mathrm{M}$ has a stopwatch $\mathrm{W}$. In addition, there is an observer A at the origin $\mathrm{O}_{\mathrm{A}}^{\prime}$ of the $x_{\mathrm{A}}^{\prime}$-axis of $S_{\mathrm{A}}^{\prime}$, and $\mathrm{A}$ has a stopwatch $\mathrm{W}_{\mathrm{A}}$. (In the following "stopwatch $\mathrm{W}$ " may be abbreviated as $\mathrm{W}$, and "stopwatch $\mathrm{W}_{\mathrm{A}}$ " as $\mathrm{W}_{\mathrm{A}}$.)

Now, when rocket A passes in front of observer $\mathrm{M}$ in $S_{\mathrm{M}}$, observer M starts $\mathrm{W}$, and observer A starts $\mathrm{W}_{\mathrm{A}}$. (see Figure 1a)

Then, when 1(s) has elapsed on $\mathrm{W}$ in $S_{\mathrm{M}}$, rocket A passes by rocket B that has approached from the forward direction. (see Figure 1b)

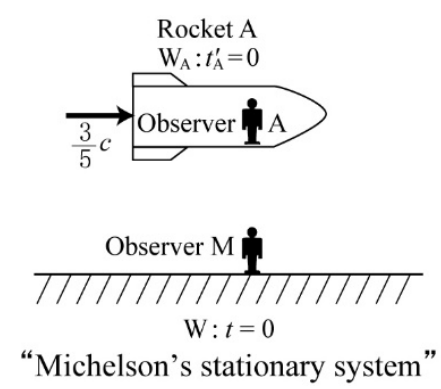

Figure 1a. When the observer on rocket A passes in front of observer M, the two observers start their own stopwatches

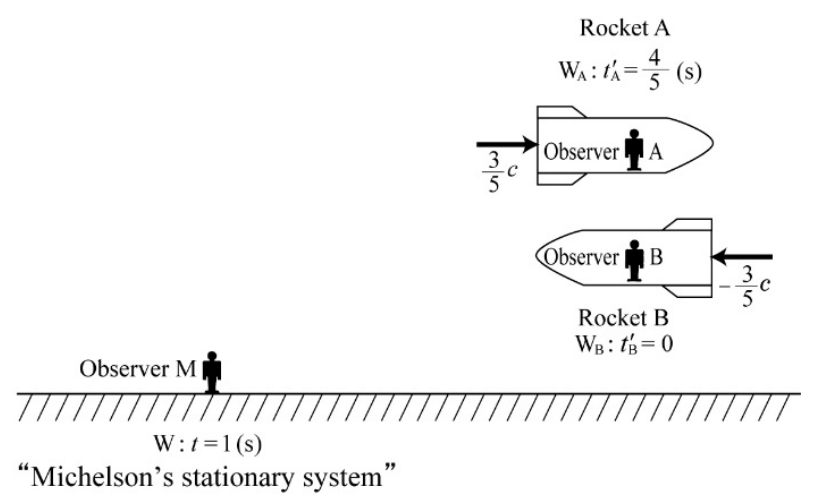

Figure $1 \mathrm{~b}$. Instant when rocket $A$ and rocket $B$ pass by each other. At this time, observer A stops $W_{A}$, and observer $\mathrm{B}$ on rocket $\mathrm{B}$ starts stopwatch $\mathrm{W}_{\mathrm{B}}$

At this time, observer A stops $\mathrm{W}_{\mathrm{A}}$, and observer $\mathrm{B}$ on rocket $\mathrm{B}$ starts stopwatch $\mathrm{W}_{\mathrm{B}}$. (However, it is assumed that the velocity of rocket B measured by an observer in $S_{\mathrm{M}}$ is $-3 c / 5$.)

According to the STR, an observer in $S_{\mathrm{M}}$ finds the following relationship between the time $t$ which elapses on W and the time $t_{\mathrm{A}}^{\prime}$ which elapses on $\mathrm{W}_{\mathrm{A}}$.

$$
t_{\mathrm{A}}^{\prime}=\frac{t}{\gamma}=t\left(1-\frac{v^{2}}{c^{2}}\right)^{1 / 2}, \quad \gamma=\left(1-\frac{v^{2}}{c^{2}}\right)^{-1 / 2} .
$$

Here, when 1(s) is substituted for $t$,

$$
t_{\mathrm{A}}^{\prime}=\frac{4}{5}(\mathrm{~s})
$$

Next, when the observer in rocket B, who continues to move at constant velocity, passes in front of observer M, the two observers stop their stopwatches (see Figure 1c). 

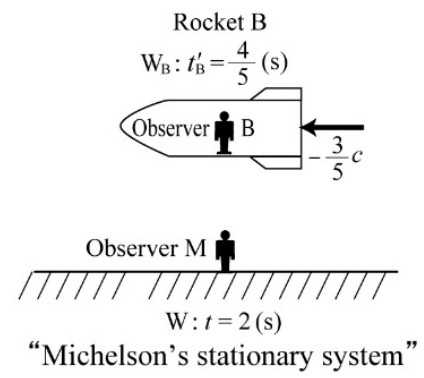

Figure 1c. When the observer on rocket B passes in front of observer M, the two observers stop their stopwatches

If the time elapsed on $\mathrm{W}_{\mathrm{B}}$ at this time is taken to be $t_{\mathrm{B}}^{\prime}$, then since $t_{\mathrm{B}}^{\prime}$ is equal to (2). That is,

$$
t_{\mathrm{B}}^{\prime}=\frac{4}{5}(\mathrm{~s}) \text {. }
$$

On the other hand, the time elapsed on $\mathrm{W}$ in $S_{\mathrm{M}}$ is $2(\mathrm{~s})$. According to the STR, during the interval where 1 (s) elapses on $\mathrm{W}$, both the time $t_{\mathrm{A}}^{\prime}$ which elapses on $\mathrm{W}_{\mathrm{A}}$ and the time $t_{\mathrm{B}}^{\prime}$ which elapses on $\mathrm{W}_{\mathrm{B}}$ are both $4 / 5(\mathrm{~s})$.

Therefore, an observer in $S_{\mathrm{M}}$ derives the following relationship from $t, t_{\mathrm{A}}^{\prime}$ and $t_{\mathrm{B}}^{\prime}$.

$$
\begin{gathered}
\frac{t}{2}=1(\mathrm{~s}), \quad t_{\mathrm{A}}^{\prime}=\frac{4}{5}(\mathrm{~s}), \quad t_{\mathrm{B}}^{\prime}=\frac{4}{5}(\mathrm{~s}) . \\
t=2(\mathrm{~s}), \quad t_{\mathrm{A}}^{\prime}+t_{\mathrm{B}}^{\prime}=\frac{8}{5}(\mathrm{~s}) .
\end{gathered}
$$

The time $\left(t_{\mathrm{A}}^{\prime}+t_{\mathrm{B}}^{\prime}\right)$ which passes on rockets A and B moving at constant velocity is delayed compared to the time $t$ which elapses in $S_{\mathrm{M}}$. Thought experiment 1 is an experiment in which accelerated movement has been removed from the famous twin paradox, and is called the "triplet thought experiment." (In this case, the triplets correspond to $\mathrm{W}, \mathrm{W}_{\mathrm{A}}$ and $\mathrm{W}_{\mathrm{B}}$ ). Here, this thought experiment is explained using Minkowski diagram 1 (see Figure 2).

The following explanation in this section is an excerpt from another paper (Suto, 2016).

Point $\mathrm{O}$ indicates both origins: $x=0, t=0$ and $x_{\mathrm{A}}^{\prime}=0, t_{\mathrm{A}}^{\prime}=0$. The point event $\mathrm{M}_{0}$ of the point light source $\mathrm{O}$ and the point event $\mathrm{A}_{0}$ of the point light source $\mathrm{O}_{\mathrm{A}}^{\prime}$ are at the origin $\mathrm{O}$. (Here, the subscripts " 0 " of the point events $\mathrm{M}_{0}$ and $\mathrm{A}_{0}$ mean, respectively, $t=0$ and $t_{\mathrm{A}}^{\prime}=0$.)

The $x$-axis indicates the $x$-axis of the inertial frame $S_{\mathrm{M}}$ when $t=0$. In addition, the $x_{\mathrm{A}}^{\prime}$-axis indicates the $x_{\mathrm{A}}^{\prime}$ -axis of the inertial frame $S_{\mathrm{A}}^{\prime}$ when $t_{\mathrm{A}}^{\prime}=0$. (However, the $x_{\mathrm{B}}^{\prime}$-axis is omitted for brevity.)

The $c t$-axis is the path for $x=0$. Put another way, it is the world line of the origin of $S_{\mathrm{M}}$. The $c t_{\mathrm{A}}^{\prime}$-axis is the world line of the origin of $S_{\mathrm{A}}^{\prime}$. Also, the $c t_{\mathrm{B}}^{\prime}$-axis is the world line of the origin of $S_{\mathrm{B}}^{\prime}$.

In addition, the straight line extending at a $45^{\circ}$ angle from the origin $\mathrm{O}$ indicates the light signal emitted from the two light sources at the instant that $\mathrm{O}$ and $\mathrm{O}_{\mathrm{A}}^{\prime}$ pass by each other.

$\mathrm{OE}$ is the distance over which the light signal emitted from $\mathrm{O}$ propagates in the $x$-axis direction while 1(s) elapses on the stopwatch $\mathrm{W}$ in $S_{\mathrm{M}}$.

$\mathrm{OE}^{\prime}$ is the distance over which the light signal emitted from $\mathrm{O}_{\mathrm{A}}^{\prime}$ propagates in the $x_{\mathrm{A}}^{\prime}$-axis direction while $1(\mathrm{~s})$ elapses on the stopwatch $\mathrm{W}_{\mathrm{A}}$ in $S_{\mathrm{A}}^{\prime}$.

Oe is the value when an observer in $S_{\mathrm{M}}$ measures the distance $\mathrm{OE}^{\prime}$, and $\mathrm{Oe}^{\prime}$ is the value when the distance OE is measured by an observer in $S_{\mathrm{A}}^{\prime}$. However, $\mathrm{Ee}^{\prime}$ is parallel to the $c t$-axis, and $\mathrm{eE}^{\prime}$ is parallel to the $c t_{\mathrm{A}}^{\prime}$-axis. Therefore, the relationship between $\mathrm{OE}, \mathrm{OE}^{\prime}, \mathrm{Oe}$ and $\mathrm{Oe}^{\prime}$ is as follows.

$$
\frac{\mathrm{Oe}}{\mathrm{OE}^{\prime}}=\frac{\mathrm{Oe}^{\prime}}{\mathrm{OE}}=\frac{1}{\gamma} \text {. }
$$

If a point is plotted on the $c t$-axis at a distance equal to $\mathrm{OE}$ from $\mathrm{O}$, that is the point event $\mathrm{M}_{1}$ for $\mathrm{O}$ at $t=1(\mathrm{~s})$.

Also, if a point is plotted on the $c t_{\mathrm{A}}^{\prime}$-axis at a distance equal to $\mathrm{OE}^{\prime}$ from $\mathrm{O}$, that is the point event $\mathrm{A}_{1}$ for $\mathrm{O}_{\mathrm{A}}^{\prime}$ at $t_{\mathrm{A}}^{\prime}=1(\mathrm{~s})$. 
Now, how should we find the relationship between the times which elapse in the stationary system and in the coordinate system of rocket A?

To find that, it is enough to compare the times when the straight line parallel to the $x$-axis intersects with the $c t$ axis and $c t_{\mathrm{A}}^{\prime}$-axis.

For example, among the lines which pass through $\mathrm{M}_{1}$, the straight line parallel with the $x$-axis intersects the $c t_{\mathrm{A}}^{\prime}$ axis at point $\mathrm{A}_{4 / 5}$, and this is the point event of the origin of $S_{\mathrm{A}}^{\prime}\left(\mathrm{W}_{\mathrm{A}}\right)$ when $t=1(\mathrm{~s})$. Therefore $t_{\mathrm{A}}^{\prime}$ matches with (2).

The point events $\mathrm{A}_{4 / 5}$ and $\mathrm{B}_{0}$ are the point events of the two at the instant when the origins of rocket $\mathrm{A}$ and $\mathrm{B}$ pass by each other. Also, the point events $\mathrm{M}_{2}$ and $\mathrm{B}_{4 / 5}$ are the point events of the two at the instant when the origin of rocket $\mathrm{B}$ passes in front of the origin of $\mathrm{S}_{\mathrm{M}}$.

The point events $A_{2}$ and $C_{4 / 5}$ are the point events of the two at the instant when the origin of rocket $C$ has caught up with the origin of rocket $\mathrm{A}$.

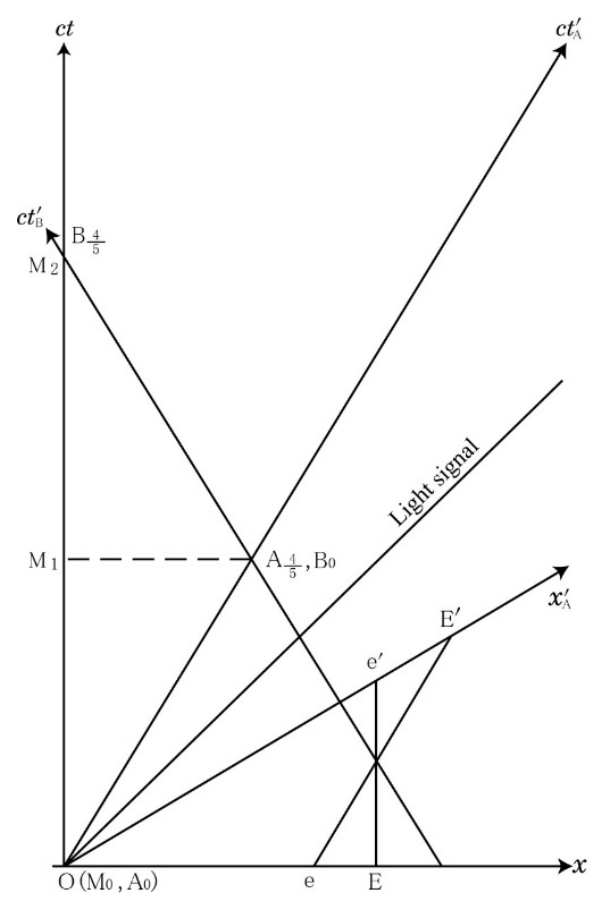

Figure 2. Minkowski diagram 1: This diagram corresponds to thought experiment 1

\section{Triplet thought Experiment 2}

In this case, rocket $\mathrm{C}$ is taken to be the subject of consideration instead of rocket $\mathrm{B}$. In the first stage, just as in thought experiment 1 , observers $\mathrm{M}$ and $\mathrm{A}$ start their own stopwatches $\mathrm{W}$ and $\mathrm{W}_{\mathrm{A}}$ when observer A in $S_{\mathrm{A}}^{\prime}$ passes in front of observer $\mathrm{M}$ in $S_{\mathrm{M}}$. (see Figure 1a).

After that, when $4 / 5$ (s) has elapsed on $\mathrm{W}$ in $S_{\mathrm{M}}$, rocket C passes in front of observer M at constant velocity $\boldsymbol{u}$. When observer $\mathrm{C}$ on rocket $\mathrm{C}$ passes in front of observer $\mathrm{M}$, observer $\mathrm{M}$ stops $\mathrm{W}$, and observer $\mathrm{C}$ starts stopwatch $\mathrm{W}_{\mathrm{C}}$ (see Figure 3a).

Here, the velocity $\boldsymbol{u}$ is the velocity at which rocket $\mathrm{C}$ approaches rocket $\mathrm{A}$ at a speed of $3 c / 5$.

Incidentally, the velocity addition law in the STR is given by the following equation.

$$
u=\frac{v+w}{1+\frac{v w}{c^{2}}} .
$$

To obtain the velocity of rocket $\mathrm{C}$ as seen from $S_{\mathrm{M}}$, it is enough to substitute $3 c / 5$ for $v$ and $w$ in this equation, and thus $u$ is: 


$$
u=\frac{15}{17} c .
$$

Rocket $\mathrm{C}$ continues its motion at constant velocity, and when it has caught up with rocket $\mathrm{A}$, observer $\mathrm{A}$ stops $\mathrm{W}_{\mathrm{A}}$ and observer $\mathrm{C}$ stops $\mathrm{W}_{\mathrm{C}}$ (see Figure $3 b$ ).

The situation of the thought experiment thus far can be explained with the following Minkowski diagram 2 (see Figure 4).

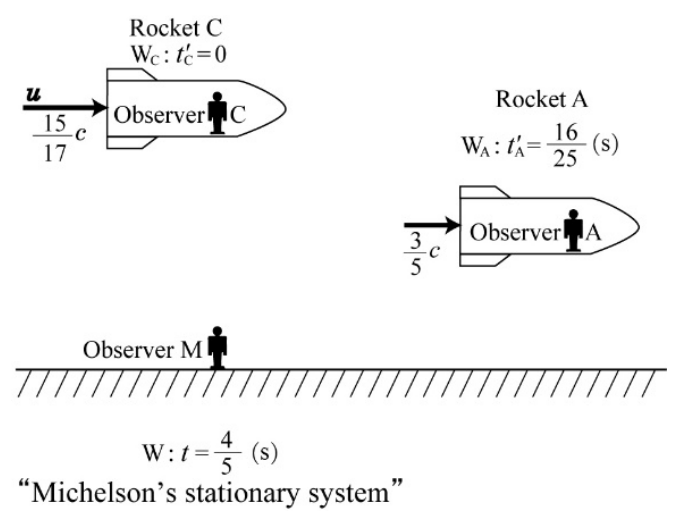

Figure 3a. Instant when $4 / 5(\mathrm{~s})$ has elapsed on $\mathrm{W}$ in the stationary system, and $\mathrm{W}_{\mathrm{C}}$ of rocket $\mathrm{C}$ passes in front of observer $\mathrm{M}$

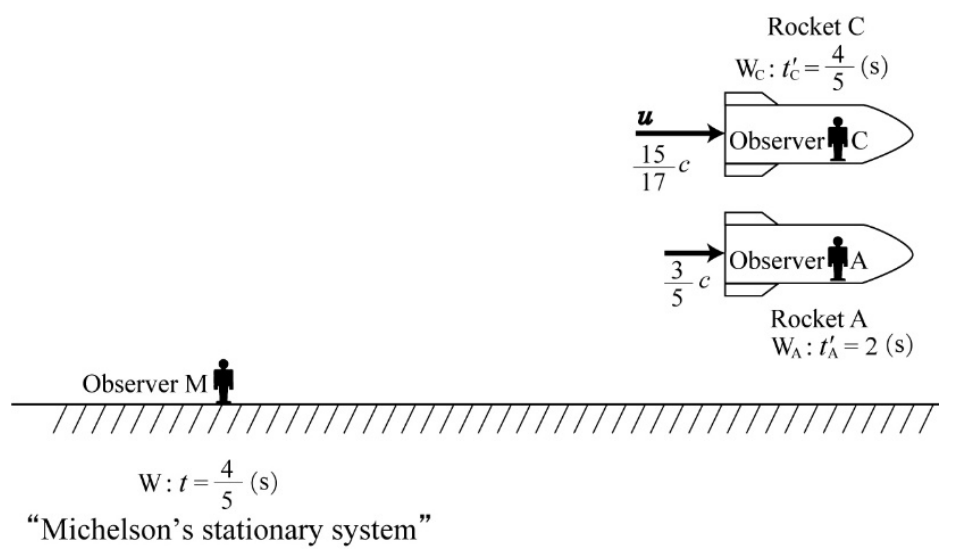

Figure $3 \mathrm{~b}$. When rocket $\mathrm{C}$ has caught up with rocket $\mathrm{A}$, observers $\mathrm{A}$ and $\mathrm{C}$ stop $\mathrm{W}_{\mathrm{A}}$ and $\mathrm{W}_{\mathrm{C}}$

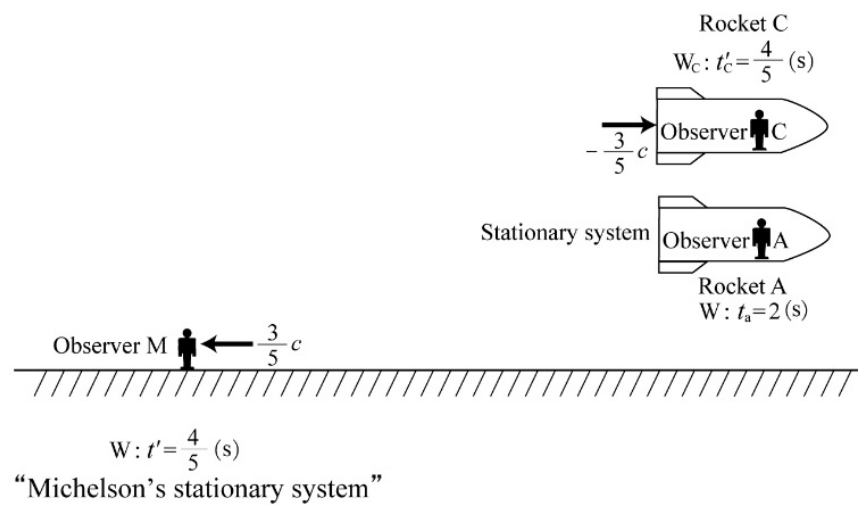

Figure 3c. Thought experiment 2 can be interpreted as indicating that observer A has carried out thought experiment 1 , taking $S_{\mathrm{A}}^{\prime}$ as the stationary system 


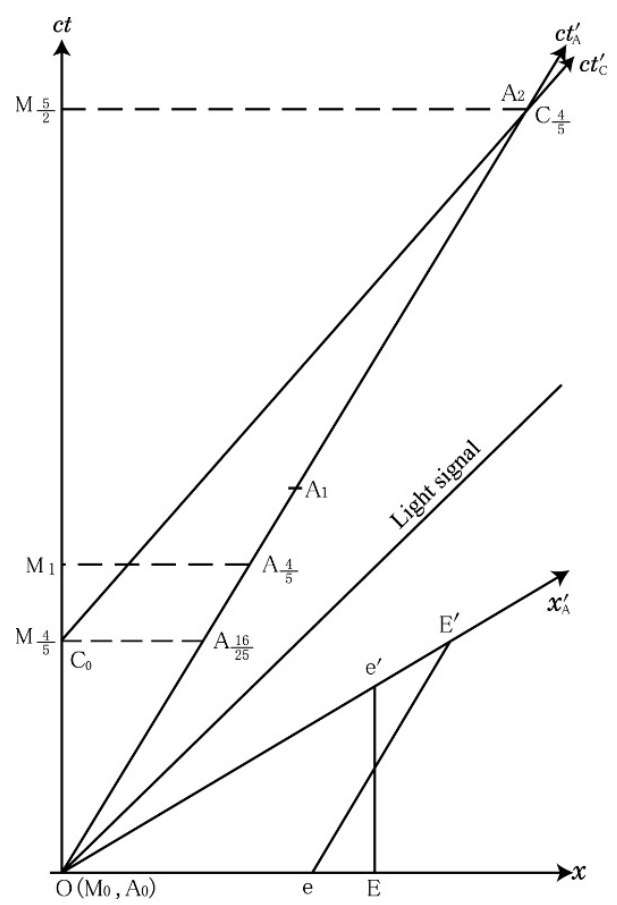

Figure 4. Minkowski diagram 2: This diagram corresponds to thought experiment 2

The $c t_{\mathrm{C}}^{\prime}$-axis of diagram 2 corresponds to the world line of the origin of $S_{\mathrm{C}}^{\prime}\left(\mathrm{W}_{\mathrm{C}}\right)$. In addition, the point events at the instant that $\mathrm{W}$ and $\mathrm{W}_{\mathrm{C}}$ pass by each other are $\mathrm{M}_{4 / 5}$ and $\mathrm{C}_{0}$. Furthermore, the point events $\mathrm{W}_{\mathrm{A}}$ and $\mathrm{W}_{\mathrm{C}}$ when rocket $\mathrm{C}$ has arrived at rocket $\mathrm{A}$ are $\mathrm{A}_{2}$ and $\mathrm{C}_{4 / 5}$.

Also, in thought experiment 2, the observer in $S_{\mathrm{M}}$ compares the time $t_{\mathrm{A}}^{\prime}$ elapsed on $\mathrm{W}_{\mathrm{A}}$ with the value $\left(t+t_{\mathrm{C}}^{\prime}\right)$ obtained by totaling the time $t$ elapsed on $\mathrm{W}$ with the time $t_{\mathrm{C}}^{\prime}$ elapsed on $\mathrm{W}_{\mathrm{C}}$. Prior to that, the observer in $S_{\mathrm{M}}$ compares $t$ with $t_{\mathrm{A}}^{\prime}$ and $t_{\mathrm{C}}^{\prime}$.

In order to find $t_{\mathrm{A}}^{\prime}$ and $t_{\mathrm{C}}^{\prime}$, we first find $t_{\mathrm{A}}$ and $t_{\mathrm{C}}$ defined as follows. When $t_{\mathrm{A}}$ elapses on $\mathrm{W}, t_{\mathrm{A}}^{\prime}$ elapses on $\mathrm{W}_{\mathrm{A}}$, and when $t_{\mathrm{C}}$ elapses on $\mathrm{W}, t_{\mathrm{C}}^{\prime}$ elapses on $\mathrm{W}_{\mathrm{C}}$. At this time, the following two equations hold.

$$
\begin{aligned}
& t_{\mathrm{A}}=\frac{4}{5}+t_{\mathrm{C}} . \\
& v t_{\mathrm{A}}=u t_{\mathrm{C}} .
\end{aligned}
$$

Equations (9) and (10) are equations for finding the point (time) where the $c t_{\mathrm{A}}^{\prime}$-axis and $c t_{\mathrm{C}}^{\prime}$-axis intersect in Minkowski diagram 2. Here, the world lines over which $\mathrm{W}_{\mathrm{A}}$ and $\mathrm{W}_{\mathrm{C}}$ are operating are $\mathrm{A}_{0} \mathrm{~A}_{2}$ and $\mathrm{C}_{0} \mathrm{C}_{4 / 5}$. That is, the instant when $\mathrm{W}_{\mathrm{C}}$ has caught up with $\mathrm{W}_{\mathrm{A}}$ is the intersection of the two world lines $\mathrm{A}_{2}$ and $\mathrm{C}_{4 / 5}$. The following shows the work of logically finding a solution, which can be easily obtained by using diagram 2 .

First, the following equation is obtained from Equations (9) and (10).

$$
t_{\mathrm{A}}=\frac{4}{5} \frac{u}{u-v} .
$$

Here, if $3 c / 5$ is substituted for $v$, and the value of (8) is substituted for $u$,

$$
t_{\mathrm{A}}=2.5(\mathrm{~s}) \text {. }
$$

Here, $t_{\mathrm{A}}$ is the time elapsed on $\mathrm{W}$ during the $2(\mathrm{~s})$ when $\mathrm{W}_{\mathrm{A}}$ was operating.

Also, from Equations (9) and (12),

$$
t_{\mathrm{C}}=\left(t_{\mathrm{A}}-\frac{4}{5}\right)=1.7(\mathrm{~s}) .
$$

Here, $t_{\mathrm{C}}$ is the time elapsed on $\mathrm{W}$ during the interval when $\mathrm{W}_{\mathrm{C}}$ was operating.

On the other hand, the time $t_{\mathrm{A}}^{\prime}$ elapsed in $S_{\mathrm{A}}^{\prime}$ is, 


$$
t_{\mathrm{A}}^{\prime}=\frac{t_{\mathrm{A}}}{\gamma}=2(\mathrm{~s}) \text {. }
$$

If $t_{\mathrm{C}}^{\prime}$ is taken to be the time which elapses on $\mathrm{W}_{\mathrm{C}}$ while $t_{\mathrm{C}}$ elapses on $\mathrm{W}$,

$$
t_{\mathrm{C}}^{\prime}=\frac{t_{\mathrm{C}}}{\gamma^{\prime}}, \quad \gamma^{\prime}=\left(1-\frac{u^{2}}{c^{2}}\right)^{-1 / 2} .
$$

Here, when the value of (8) is substituted for $u$ in Equation (15),

$$
\gamma^{\prime}=\frac{17}{8}
$$

To find $t_{\mathrm{C}}^{\prime}$, it is sufficient to substitute the value of (13) for $t_{\mathrm{C}}$ in Equation (15), and thus

$$
t_{\mathrm{C}}^{\prime}=\frac{4}{5}(\mathrm{~s})
$$

This $t_{\mathrm{C}}^{\prime}$ is the time over which $\mathrm{W}_{\mathrm{C}}$ was operating. Due to the above considerations, the observer $\mathrm{M}$ in $S_{\mathrm{M}}$ obtains the following values for the elapsed times of $t, t_{\mathrm{A}}^{\prime}$ and $t_{\mathrm{C}}^{\prime}$.

$$
\begin{gathered}
\frac{t_{\mathrm{A}}^{\prime}}{2}=1(\mathrm{~s}), \quad t=\frac{4}{5}(\mathrm{~s}), \quad t_{\mathrm{C}}^{\prime}=\frac{4}{5}(\mathrm{~s}) . \\
t_{\mathrm{A}}^{\prime}=2(\mathrm{~s}), \quad t+t_{\mathrm{C}}^{\prime}=\frac{8}{5}(\mathrm{~s}) .
\end{gathered}
$$

The value $\left(t+t_{\mathrm{C}}^{\prime}\right)$ obtained by totaling the times elapsed on $\mathrm{W}$ and $\mathrm{W}_{\mathrm{C}}$ is delayed compared to the time $t_{\mathrm{A}}^{\prime}$ which elapses in $S_{\mathrm{A}}^{\prime}$ which is not originally the stationary system.

The observer in rocket A regards his own coordinate system as a stationary system.

Therefore, Equations (18) and (19) are interpreted as follows. (note the change in the dash ' indicating the moving system due to the change in the stationary system.)

$$
\begin{gathered}
\frac{t_{\mathrm{A}}}{2}=1(\mathrm{~s}), \quad t^{\prime}=\frac{4}{5}(\mathrm{~s}), \quad t_{\mathrm{C}}^{\prime}=\frac{4}{5}(\mathrm{~s}) . \\
t_{\mathrm{A}}=2(\mathrm{~s}), \quad t^{\prime}+t_{\mathrm{C}}^{\prime}=\frac{8}{5}(\mathrm{~s}) .
\end{gathered}
$$

Equation (21) can be interpreted as indicating that observer A has conducted the "triplet thought experiment". (Figure 3c) Equations (5) and (21) are the experiment results predicted by the STR.

\section{Discussion}

Let us consider, as far as possible, the a priori rhythm by which the stopwatches used in thought experiments 1 and 2 mark off time. The problem of rhythm cannot be addressed in the STR, but this paper has introduced $S_{\mathrm{M}}$ and thus it is possible to discuss the problem of rhythm.

Now, if the rhythms by which the three stopwatches mark time are expressed as rhythm $(\mathrm{W})$, rhythm $\left(\mathrm{W}_{\mathrm{A}}\right)$ and rhythm $\left(\mathrm{W}_{\mathrm{B}}\right)$, then observer $\mathrm{M}$ can predict the following relationship from (4).

$$
\text { rhythm }(\mathrm{W}) \text { : rhythm }\left(\mathrm{W}_{\mathrm{A}}\right) \text { : rhythm }\left(\mathrm{W}_{\mathrm{B}}\right)=1: \frac{4}{5}: \frac{4}{5} \text {. }
$$

Also, in thought experiment 2, observer M can predict the following relationship if (16) is taken into account.

$$
\text { rhythm }\left(\mathrm{W}_{\mathrm{A}}\right) \text { : rhythm }(\mathrm{W}) \text { : rhythm }\left(\mathrm{W}_{\mathrm{C}}\right)=\frac{4}{5}: 1: \frac{8}{17} \text {. }
$$

In contrast, the observer in rocket A regards his own coordinate system as a stationary system, and interpreted the situation as in (20). However, the problem of rhythm cannot be addressed with the STR, and thus the observer in rocket A cannot make the following prediction from (20). That is,

$$
\text { rhythm }\left(\mathrm{W}_{\mathrm{A}}\right) \text { : rhythm }(\mathrm{W}): \text { rhythm }\left(\mathrm{W}_{\mathrm{C}}\right) \neq 1: \frac{4}{5}: \frac{4}{5} \text {. }
$$


Rhythm is an a priori concept, and thus it is not possible for all observers to assert that there will be delay in the rhythm of a clock in an inertial frame moving at constant velocity relative to their own inertial frame.

\section{Conclusion}

In this paper, the observers $\mathrm{M}$ and $\mathrm{A}$ carry out the triplet thought experiment. The observer in $\mathrm{S}_{\mathrm{M}}$ makes the following predictions of the total $\left(t_{\mathrm{A}}^{\prime}+t_{\mathrm{B}}^{\prime}\right)$ of the time $t_{\mathrm{A}}^{\prime}$ elapsed in $\mathrm{S}_{\mathrm{A}}$ and the time $t_{\mathrm{B}}^{\prime}$ elapsed in $\mathrm{S}_{\mathrm{B}}$, and the time $t$ elapsed in $\mathrm{S}_{\mathrm{M}}$.

$$
t=2(\mathrm{~s}), \quad t_{\mathrm{A}}^{\prime}+t_{\mathrm{B}}^{\prime}=\frac{8}{5}(\mathrm{~s})
$$

Also, $\mathrm{S}_{\mathrm{M}}$ is a special coordinate system where light propagates isotropically, and therefore, the rhythm whereby the clock marks off time is predicted as follows.

$$
\text { rhythm }(\mathrm{W}): \text { rhythm }\left(\mathrm{W}_{\mathrm{A}}\right) \text { : rhythm }\left(\mathrm{W}_{\mathrm{B}}\right)=1: \frac{4}{5}: \frac{4}{5} \text {. }
$$

In addition, this paper, which assumes the existence of $\mathrm{S}_{\mathrm{M}}$, makes predictions as follows for the first half of thought experiment 2 .

$$
t_{\mathrm{A}}^{\prime}=2(\mathrm{~s}), \quad t+t_{\mathrm{C}}^{\prime}=\frac{8}{5}(\mathrm{~s}) .
$$

Also, the observer in $\mathrm{S}_{\mathrm{M}}$ makes the following predictions based on (2) and (16).

$$
\text { rhythm }\left(\mathrm{W}_{\mathrm{A}}\right) \text { : rhythm }(\mathrm{W}) \text { : rhythm }\left(\mathrm{W}_{\mathrm{C}}\right)=\frac{4}{5}: 1: \frac{8}{17} \text {. }
$$

In contrast, the observer $\mathrm{A}$ who regards his own coordinate system as a stationary system makes the following prediction regarding the time $t_{\mathrm{A}}$ elapsed on rocked A and $\left(t^{\prime}+t_{\mathrm{C}}^{\prime}\right)$.

$$
t_{\mathrm{A}}=2(\mathrm{~s}), \quad t^{\prime}+t_{\mathrm{C}}^{\prime}=\frac{8}{5}(\mathrm{~s}) .
$$

However, the STR cannot handle the problem of rhythm. Therefore, observer A cannot assert the following relationship. That is,

$$
\text { rhythm }\left(\mathrm{W}_{\mathrm{A}}\right) \text { : rhythm }(\mathrm{W}): \text { rhythm }\left(\mathrm{W}_{\mathrm{C}}\right) \neq 1: \frac{4}{5}: \frac{4}{5} \text {. }
$$

In the end, (19) holds because (23) holds. However, observer A carries out the thought experiment with the conviction that his own coordinate system is a stationary system, and thus a result (21) is obtained which agrees with the predictions of the STR.

Rocket A undergoes accelerated motion until it attains motion at constant velocity. The coordinate system of rocket A is clearly a moving system. The two inertial frames $\mathrm{M}$ and $\mathrm{A}$ are by no means equivalent. Even so, the author was able to confirm the delay in time predicted by the STR even in the triplet thought experiment carried out by observer A.

This paper concludes that the traditional interpretation of the twin paradox described in the introduction must be revised.

\section{Acknowledgments}

I would like to express my thanks to the staff at ACN Translation Services for their translation assistance. Also, I wish to express my gratitude to Mr. H. Shimada for drawing figures.

\section{Appendix: Time that is Actually Adjusted in Synchronization of the Two Clocks}

Let there be a given stationary rigid rod of length $L_{0}$ as measured by a ruler which is stationary, and assume that the rod is placed along the positive direction of the Michelson's stationary system's $x$-axis.

Assume that clocks A and B of the same type are set up at points $A$ and $B$ on the rear and front end of this rod. Here clock $A$ will be abbreviated as $C_{A}$, and clock $B$ as $C_{B}$.

Suppose a ray of light is emitted in the direction of $\mathrm{B}$ from $\mathrm{A}$ at time $t_{\mathrm{A}}$ of $\mathrm{C}_{\mathrm{A}}$, reaches and is reflected at $\mathrm{B}$ at time $t_{\mathrm{B}}$ of $\mathrm{C}_{\mathrm{B}}$, and then returns to $\mathrm{A}$ at time $t_{\mathrm{A}^{\prime}}$ of $\mathrm{C}_{\mathrm{A}}$. Einstein determined that if the following relationships hold between these times, then the two clocks represent the same time by definition (Einstein, 1923). 


$$
t_{\mathrm{B}}-t_{\mathrm{A}}=t_{\mathrm{A}^{\prime}}-t_{\mathrm{B}} \text {. }
$$

If the relationship in (A1) does not hold for the times of $\mathrm{C}_{\mathrm{A}}$ and $\mathrm{C}_{\mathrm{B}}$, then it is necessary to adjust the time of $\mathrm{C}_{\mathrm{B}}$ so that the relationship in (A1) holds. (Actually, either clock can be adjusted.)

First, times are set so that the relation in (A1) holds for $C_{A}$ and $C_{B}$. That rod begins to move at constant velocity $v$ relative to the stationary system $S_{\mathrm{M}}$. (see Figure 5)
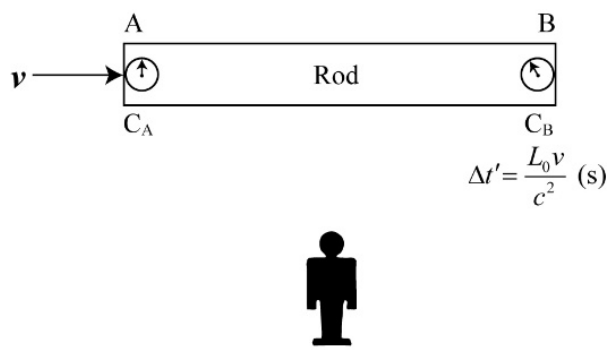

“Michelson's stationary system"

Figure 5. A rod is moving at the constant velocity $v$ relative to the Michelson's stationary system. In this case, if the time adjustment $\Delta t^{\prime}$ performed with clock B of the rod is predicted by an observer in the stationary system, it will be $L_{0} v / c^{2}(\mathrm{~s})$

Now when the time required for the light signal emitted from point $\mathrm{A}$ at the rear of the rod to travel from point $\mathrm{A}$ to point B is measured with the clock in $S_{\mathrm{M}}$, it is $\left(t_{\mathrm{B}}-t_{\mathrm{A}}\right)$ by the definition in (A1). Also, if this time is measured with the clock in the moving system $S^{\prime}$, it is expressed as $\left(t_{\mathrm{B}}^{\prime}-t_{\mathrm{A}}^{\prime}\right)$.

According to the STR, the rod seen from $S_{\mathrm{M}}$ contracts by $1 / \gamma$ times in the direction of motion. Also, the light speed in vacuum does not depend on the speed of the light source.

Thus $\left(t_{\mathrm{B}}-t_{\mathrm{A}}\right)$ is given by the following equation.

$$
t_{\mathrm{B}}-t_{\mathrm{A}}=\frac{L_{0}}{c-v}\left(1-\frac{v^{2}}{c^{2}}\right)^{1 / 2}(\mathrm{~s}) .
$$

Also, the time $\left(t_{\mathrm{A}^{\prime}}-t_{\mathrm{B}}\right)$ required for the light signal to return from point $\mathrm{B}$ to point $\mathrm{A}$ is given by the following equation.

$$
t_{\mathrm{A}^{\prime}}-t_{\mathrm{B}}=\frac{L_{0}}{c+v}\left(1-\frac{v^{2}}{c^{2}}\right)^{1 / 2}(\mathrm{~s})
$$

However, the denominator on the right side of Equations (A2) and (A3) does not signify that the light speed changes.

According to the STR, the relationship of $\left(t_{\mathrm{B}}^{\prime}-t_{\mathrm{A}}^{\prime}\right)$ and $\left(t_{\mathrm{B}}-t_{\mathrm{A}}\right)$ is:

$$
\left(t_{\mathrm{B}}^{\prime}-t_{\mathrm{A}}^{\prime}\right)=\left(t_{\mathrm{B}}-t_{\mathrm{A}}\right)\left(1-\frac{v^{2}}{c^{2}}\right)^{1 / 2} .
$$

Here, if the right side of Equation (A2) is substituted for $\left(t_{\mathrm{B}}-t_{\mathrm{A}}\right)$ in Equation (A4),

$$
t_{\mathrm{B}}^{\prime}-t_{\mathrm{A}}^{\prime}=\frac{L_{0}(c+v)}{c^{2}}(\mathrm{~s}) .
$$

Similarly, if the time $\left(t_{\mathrm{A}^{\prime}}^{\prime}-t_{\mathrm{B}}^{\prime}\right)$ which passes on the clock in $S^{\prime}$ while the light signal returns from point B to point $\mathrm{A}$ is,

$$
t_{\mathrm{A}^{\prime}}^{\prime}-t_{\mathrm{B}}^{\prime}=\frac{L_{0}(c-v)}{c^{2}}(\mathrm{~s})
$$


If we set $t_{\mathrm{A}}^{\prime}=0$ to simplify the equation, $t_{\mathrm{A}^{\prime}}^{\prime}$ becomes the time which passes in $S^{\prime}$ while the light signal makes a round trip between $\mathrm{A}$ and $\mathrm{B}$. Thus, the observer in $S^{\prime}$ determines that the time of $\mathrm{C}_{\mathrm{B}}$ when the light has arrived at $\mathrm{B}$ is $t_{\mathrm{A}^{\prime}}^{\prime} / 2$. This time can be found from Equations (A5) and (A6). That is,

$$
\begin{gathered}
\frac{1}{2} t_{\mathrm{A}^{\prime}}^{\prime}=\frac{1}{2}\left[\left(t_{\mathrm{B}}^{\prime}-t_{\mathrm{A}}^{\prime}\right)+\left(t_{\mathrm{A}^{\prime}}^{\prime}-t_{\mathrm{B}}^{\prime}\right)\right] \\
=\frac{L_{0}}{c}(\mathrm{~s}) .
\end{gathered}
$$

However, since $L_{0}(c+v) / c^{2}>L_{0} / c$, the time on $\mathrm{C}_{\mathrm{B}}$ must be later than the time on $\mathrm{C}_{\mathrm{A}}$ to resolve this discrepancy. If this adjustment time is taken to be $\Delta t^{\prime}$,

$$
\begin{gathered}
\Delta t^{\prime}=\left(t_{\mathrm{B}}^{\prime}-t_{\mathrm{A}}^{\prime}\right)-\frac{1}{2} t_{\mathrm{A}^{\prime}}^{\prime} \\
=\frac{L_{0} v}{c^{2}}(\mathrm{~s}) .
\end{gathered}
$$

If the time of $\mathrm{C}_{\mathrm{B}}$ is delayed by $L_{0} v / c^{2}(\mathrm{~s})$, then a state is achieved where the times of $\mathrm{C}_{\mathrm{A}}$ and $\mathrm{C}_{\mathrm{B}}$ can be said to be simultaneous in $S^{\prime}$.

Also, at the time $\Delta t^{\prime}=L_{0} v / c^{2}(\mathrm{~s})$, it can be determined that the coordinate system where the rod was initially stationary was the coordinate system where light propagates isotropically. On the other hand, at the time $\Delta t^{\prime} \neq L_{0} v / c^{2}(\mathrm{~s})$, it can be determined that the coordinate system where the rod was initially stationary was the coordinate system where light propagates anisotropically (Suto, 2010, 2015).

\section{References}

Einstein, A. (1923). The Principle of Relativity (p. 41). Dover Publication, Inc. New York.

Holton, G. (1963). Selected reprints in Special relativity theory. American Institute of Physics, New York.

Suto, K. (2010). Violation of the special theory of relativity as proven by synchronization of clocks. Physics Essays, 23(3), 511-519. http://dx.doi.org/10.4006/1.3474836

Suto, K. (2015). Demonstration of the existence of a velocity vector missing from the special theory of relativity. Physics Essays, 28(3), 345-351. http://dx.doi.org/10.4006/0836-1398-28.3.345

Suto, K. (2016). Thought Experiment Revealing a Contradiction in the Special Theory of Relativity. Applied Physics Research, 8(6). 70. http://dx.doi.org/10.5539/apr.v8n6p70

Suto, K. (2016). Elucidation of Time Symmetry Predicted by the Special Theory of Relativity. IOSR Journal of Applied Physics, 8(6), IV. http://dx.doi.org/10.9790/4861-0806042027

\section{Copyrights}

Copyright for this article is retained by the author(s), with first publication rights granted to the journal.

This is an open-access article distributed under the terms and conditions of the Creative Commons Attribution license (http://creativecommons.org/licenses/by/4.0/). 